\title{
NGHIÊN CỬU ỨNG DỤNG MÔ HÌNH HOÁ TÍNH TOÁN Ô NHIỄM KHÔNG KHÍ CHO NGUỒN THẢI ĐƯỜNG VÀ THỂ TÍCH - TRƯỜNG HỢP ÁP DỤNG TẠI MỎ KHAI THÁC ĐÁ TỈNH BÌNH DƯƠNG
}

\author{
Bùi Tá Long ${ }^{*}$, Nguyễn Hoàng Phong ${ }^{1}$, Nguyễn Châu Mỹ Duyên ${ }^{1}$
}

Tóm tắt: Phát thải tùu hoạt động khai thác đá là loại hình gây ô nhiếm chính cho khu vưc xung quanh với loại hình nguồn thải nguồn đường và nguồn thể tích. Mô hình hóa môi truờng là công cu không thể thiếu để đánh giá phạm vi và múc độ ảnh hưởng tù loại hình hoạt động này. Trong nhiều năm qua, đã có nhiều nghiên cứu dụa trên phương pháp mô hình toán khác nhau, đặc biệt Co quan bảo vệ môi trừ̀ng Mỹ đã đưa ra phưong pháp tính toán lưu ý tới địa hình phưc tạp và sụ thay đổi khi tương tại lớp biên khi quyển. Bài báo này, dựa trên phuơng pháp kết hợp mô hình toán, GIS, WRF tính toán ô nhiễm không khi tù nguồn thể tích và nguồn đường tù hoạt động khai thác đá tại Bình Duong. Kết quả tính toán được kiểm định tù số liệu thực đo cho thấy độ tin cậy của mô hìh được đề xuất.

Từ khóa: Mô hình phát tán, ô nhiễn buii, nguồn thể tích, nguồn đường, WRF.

Ban Biên tập nhận bài: 12/05/2019 Ngày phản biện xong: 20/06/2019 Ngày đăng bài: 25/07/2019

\section{1. Đặt vấn đề}

Công tác quản lý môi trường thường xuyên phải đối mặt với ô nhiễm không khí ở khu vực tâp trung loại hình phát thải dạng đường và vùng, ví dụ nơi khai thác đá phục vụ cho ngành xây dựng. Tùy thuộc vào vị trí, cấu trúc, dạng mỏ đá, tác động môi trường của quá trình khai thác, chế biến, vận chuyển diễn ra đa dạng và cường độ khác nhau [12]. Tác động tới môi trường không khí của hoạt động khai thác khoáng sản chủ yếu là tạo ra bụi. Bụi thường phát sinh trong quá trình nổ mìn, đào xúc đất đá, bốc xúc và vận chuyển khoáng sản. Các loại bụi này đều độc hại tới sức khỏe con người do vậy xây dựng phương pháp định lượng ô nhiễm không khí là nhiệm vụ cần giải quyết trong khuôn khổ bảo vệ môi trường và phát triển bền vững. Trong nghiên cứu này, dựa trên số liệu hiện trạng khai thác đá tại 2 mỏ khai thác Thường Tân, Tân Mỹ, tỉnh Bình Dương đưa ra đánh giá mức độ, phạm vi ảnh hưởng từ các loại hình nguồn thải khác với nguồn điểm, cụ thể là dạng đường (line source) ${ }^{1}$ Truoòng Đại học Bách Khoa Tp. HCM

Email:longbt62@hcmut.edu.vn và thể tích (volume source).

Tại Việt Nam, các nghiên cứu ứng dụng mô hình phát tán ô nhiễm không khí bắt đầu từ thế kỷ trước [1-3] và tăng nhanh sau năm 1998, xem nguồn nghiên cứu trong [3-4]. Hạn chế của các nghiên cứu trong nước [1-2] chỉ giới hạn nguồn điểm, trong [3] có xem xét một số trường hợp nguồn đường, nguồn thể tích, tuy nhiên nghiên cứu này chỉ xem xét địa hình bằng phẳng, không lưu ý tới trường hợp nguồn thải nằm trong khu vực địa hình phức tạp. Hạn chế tiếp theo của các nghiên cứu [1-3] chưa ý tới sự thay đổi yếu tố khí tượng tại lớp biên khí quyển, điều rất quan trọng trong tính toán ô nhiễm không khí. Nghiên cứu [4] đã đưa ra cách tính ô nhiễm không khí cho nguồn điểm có lưu ý tới địa hình phức tạp cũng như yếu tố khí tượng lớp biên, tuy nhiên hạn chế của nghiên cứu này là không lưu ý tới các loại hình nguồn khác như nguồn đường, nguồn thể tích. Nghiên cứu phát triển mô hình phát tán ô nhiễm không khí được thực hiện tại nhiều nước, đặc biệt là các nước phát triển, xem [5-7] và các trích dẫn trong đó, nhưng Mỹ là 
nước thực hiện công việc này có hệ thống hơn cả [8-11]. Theo Environmental Protection Agency (EPA) (1995) [8], khởi đầu từ năm 1991, Hiệp hội Khí tượng Hoa Kỳ (AMS) và Cơ quan Bảo vệ Môi trường Hoa Kỳ (EPA) đã khởi xướng một sự hợp tác với mục tiêu đưa thành tựu nghiên cứu lớp biên hành tinh (Planetary Boundary Layer, $P B L)$ vào các mô hình phân tán ô nhiễm. Kết quả của sự hợp tác này được thể hiện trong [8-11]. Tuy nhiên, hạn chế của các nghiên cứu này là kết quả viết phần mềm tính toán ít được công bố rộng rãi do vấn đề bản quyền.

Bài báo này thực hiện nghiên cứu ứng dụng mô hình hoá tính toán ô nhiễm không khí cho loại hình nguồn thải đường và thể tích, lấy khu vực mỏ khai thác đá tỉnh Bình Dương làm ví dụ nghiên cứu, bởi khu vực này đang có loại hình nguồn thải đường và nguồn thể tích đang hoạt động tích cực. Nguồn đường được xác định bởi độ dài, chiều rộng của đường và chiều cao $h=$ $2 \mathrm{~m}$ độ cao cách mặt đất nơi diễn ra phát thải (được mô tả chi tiết trong [8]). Nguồn thể tích hiểu là hình hộp với đáy là hình vuông và chiều cao $\mathrm{h}$ phụ thuộc vào trường hợp thực tế (được mô tả chi tiết trong [8]).

\section{Phương pháp và số liệu được sử dụng}

\section{1. Đối tựng, phạm vi nghiên cứu}

Tỉnh Bình Dương có 2 cụm mỏ đá xây dựng là nằm tại 2 xã Thường Tân, Tân Mỹ (Hình 1). Hai cụm mỏ này có điều kiện khai thác đá thuận lợi, nhờ vào vị trí vùng sâu, xa thị trấn, đất đai cằn cỗi sử dụng vào nông nghiệp không hiệu quả. Tuy đá tại đây chỉ có chất lượng từ trung bình đến kém, nhưng nhờ vào điều kiện giao thông thủy thuận lợi nên khu mỏ ngày càng phát triển, thị trường tiêu thụ phần lớn là vùng Đồng bằng sông Cửu Long, sản lượng hàng năm hiện nay khoảng 4-5 triệu $\mathrm{m}^{3}$.

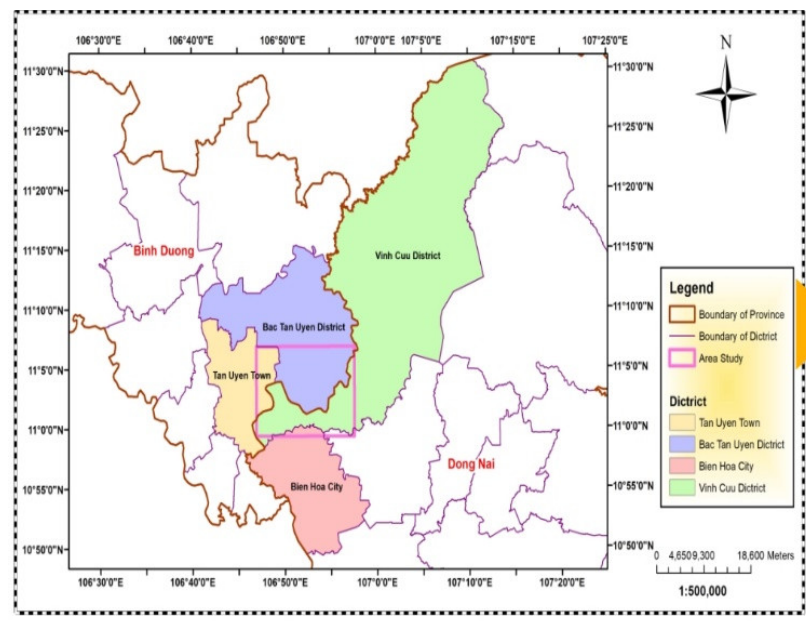

Hình 1. Bản đồ khu vục nghiên cứu

Qua khảo sát thực địa về hoạt động khai thác mỏ đá [12], nhóm nghiên cứu đã phân loại nguồn tác động ảnh hưởng đến môi trường không khí khu vực. Nguồn phát sinh nhiều bụi nhất là hoạt động xay nghiền đá tại khu vực khai thác. Loại nguồn tiếp theo là quá trình vận chuyển đá từ khu khai thác đến các bến thủy nội địa, nguồn phát thải từ quá trình tải đá lên sà lan tại bến thủy nội địa và nguồn phát thải từ hoạt động khai thác tại moong đá ở vị trí thấp hơn mặt đất.

\subsection{Mô hình phát thải}

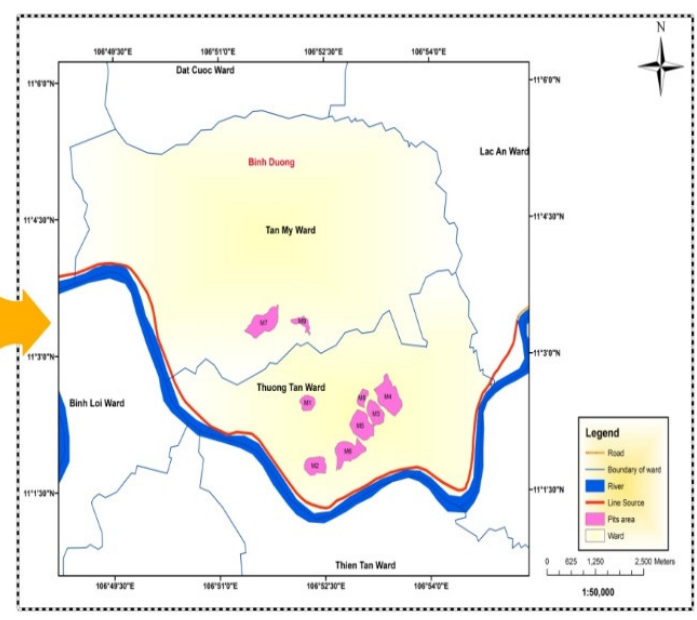

vi trí các moong khai thác đá.

Công suất nguồn thải nguồn đường được tính toán theo công thức [13-15] như sau:

$$
\mathrm{M}_{\mathrm{k}, \mathrm{i}}=\mathrm{EF}_{\mathrm{i}} \times \mathrm{Q}_{\mathrm{k}} \times \mathrm{L}_{\mathrm{k}}
$$

Trong đó $\mathrm{M}_{\mathrm{k}, \mathrm{i}}$ là công suất của nguồn thải $\mathrm{k}$ đối với thông số ô nhiễm i $(\mathrm{mg} / \mathrm{s})$. Với chỉ số nguồn thải $\mathrm{k}$ trong nghiên cứu này là 7 tuyến đường cần tính toán (xem Bảng 3 ) và $i$ là 3 thông số ô nhiễm $\mathrm{SO}_{2}, \mathrm{NO}_{2}, \mathrm{PM}_{10} ; \mathrm{Q}_{\mathrm{k}}$ là lưu lượng phương tiện giao thông của nguồn thải $\mathrm{k}$ (xe/giờ). Khảo sát, xác định loại và số lượng các phương tiện giao thông được thực hiện bằng 
phương pháp ghi hình tại các điểm nút của tuyến đường trong nhiều khung giờ liên tiếp trong ngày, mỗi giờ ghi hình 15 phút. Sau đó, thực hiện tính toán, quy đổi để thu được giá trị lưu lượng phương tiện giao thông (xe/giờ). Việc ghi hình được thực hiện vào ngày 15/07/2019; $\mathrm{L}_{\mathrm{k}}$ là chiều dài của tuyến đường $\mathrm{k}$ cần tính toán $(\mathrm{km})$; EFi là hệ số phát thải đối với thông số ô nhiễm i (g.km1.xe-1). Hệ số phát thải áp dụng tính toán trong nghiên cứu được trình bày ở Bảng 1 như sau:

Bảng 1. Hệ số phát thải của các thông số $\mathrm{SO}_{2}, \mathrm{NO}_{x}, \mathrm{PM}_{10}$

\begin{tabular}{clccc}
\hline TT & Loại phương tiện & $\mathrm{NO}_{\mathrm{x}}[13-14]$ & $\mathrm{SO}_{2}[14]$ & $\mathrm{PM}_{10}[15]$ \\
\hline 1 & Xe máy, mô tô & $0,05 \pm 0,02$ & $0,03 \pm 0,015$ & 0,2 \\
2 & Xe buýt & $19,7 \pm 5,2$ & $1,86 \pm 1,08$ & 236 \\
3 & Xe tải nhẹ (LDV) & $1,9 \pm 0,9$ & $0,05 \pm 0,029$ & 1,6 \\
4 & Xe tải nặng (HDV) & $19,7 \pm 5,2$ & $1,86 \pm 1,08$ & 236 \\
5 & Xe ô tô & $1,9 \pm 0,9$ & $0,18 \pm 0,105$ & 0,07 \\
\hline
\end{tabular}

Công thức tính phát thải tổng bụi lơ lửng như sau: (TSP) được thực hiện theo công thức [13-15]

$$
\text { Emission TSP }(\mathrm{g} / \mathrm{s})=\operatorname{CTSP}\left(\mathrm{mg} / \mathrm{m}^{3}\right) \times 1000(\mathrm{~g} / \mathrm{mg}) \times \mathrm{V}(\mathrm{m} / \mathrm{s}) \times \mathrm{S}\left(\mathrm{m}^{2}\right)
$$

Trong đó Emission TSP $(\mathrm{g} / \mathrm{s})$ là tải lượng TSP; CTSP $\left(\mathrm{mg} / \mathrm{m}^{3}\right)$ là nồng độ TSP đo đạc; $\mathrm{V}$ $(\mathrm{m} / \mathrm{s})$ là vận tốc gió tại thời điểm đo; $\mathrm{S}\left(\mathrm{m}^{2}\right)$ là diện tích moong khai thác (Bảng 4). Kết quả tính toán TSP sẽ được quy đổi sang PM10 theo phương pháp được trình bày trong [15]. Các công thứ $(1),(2)$ trong nghiên cứu này được sử dụng để tính toán thông số tải lượng, từ đó ứng dụng mô hình phát tán để tính toán phạm vi ảnh hưởng từ các nguồn thải.

\subsection{Mô hình khí tượng}

Trong nghiên cứu này sử dụng mô hình Nghiên cứu và Dự báo thời tiết (Weather Research and Forecasting (WRF)). Đây là kết quả của sự hợp tác phát triển của nhiều trung tâm nghiên cứu và dự báo khí tượng ở Hoa Kỳ như Trung tâm Quốc gia về nghiên cứu khí quyển
(NCAR), Cục Quản lý Đại dương và Khí quyển Quốc gia (NOAA), Trung tâm dự báo môi trường quốc gia (NCEP) [16]. Phiên bản đầu tiên của WRF được ra đời vào năm 2000 [17-18], và liên tiếp các năm sau đó là những phiên bản tiếp theo. Từ năm 2004 là phiên bản 2.0 và các phiên bản kế tiếp; từ năm 2008 phiên bản thứ 3 đầu tiên được cập nhật. Phiên bản này có sự cải tiến sự ổn định của lớp biên hành tinh (PBL), một số thay đổi trong sơ đồ Grell và cải tiến sơ đồ vi vậy lý mây, vật lý bề mặt,... Hiện nay, phiên bản mới nhất là 4.1 .2 (tháng 6/2019) được áp dụng cho nghiên cứu này. Các dữ liệu khí tượng này được sử dụng tính toán sự thay đổi theo phương đứng của gió, dòng chảy rối và nhiệt độ. Các bước triết xuất này được thề hiện trên Hình 2.

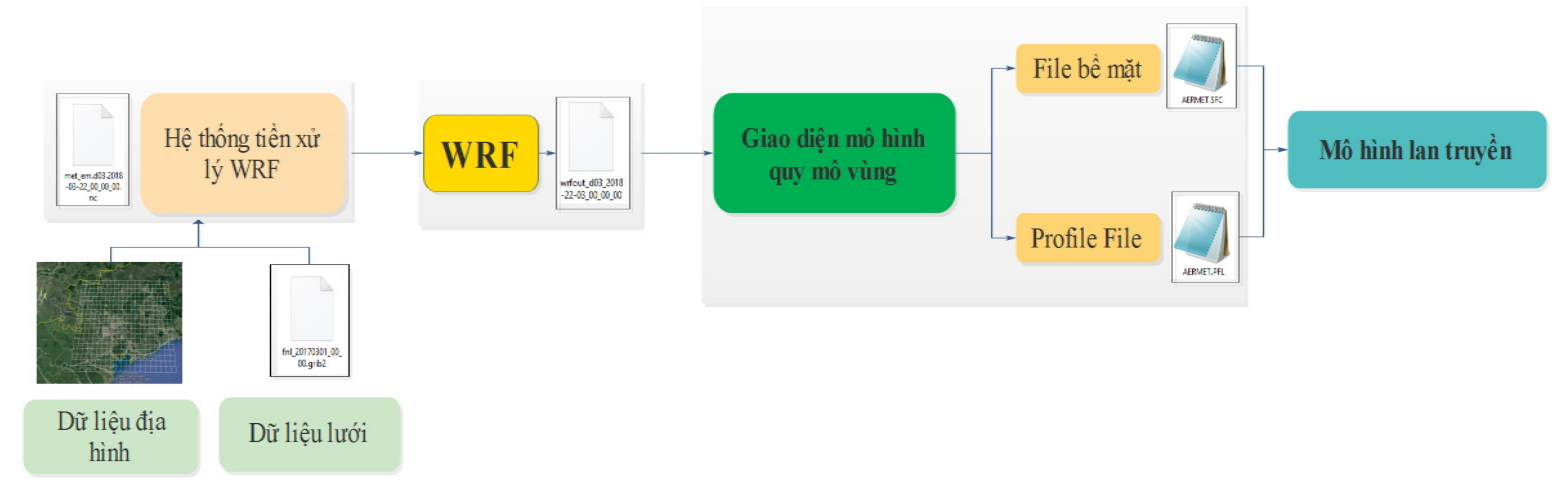

Hình 2. Các buớc xủ lý sinh ra số liệu khi tương lớp biên khí quyển [4] 


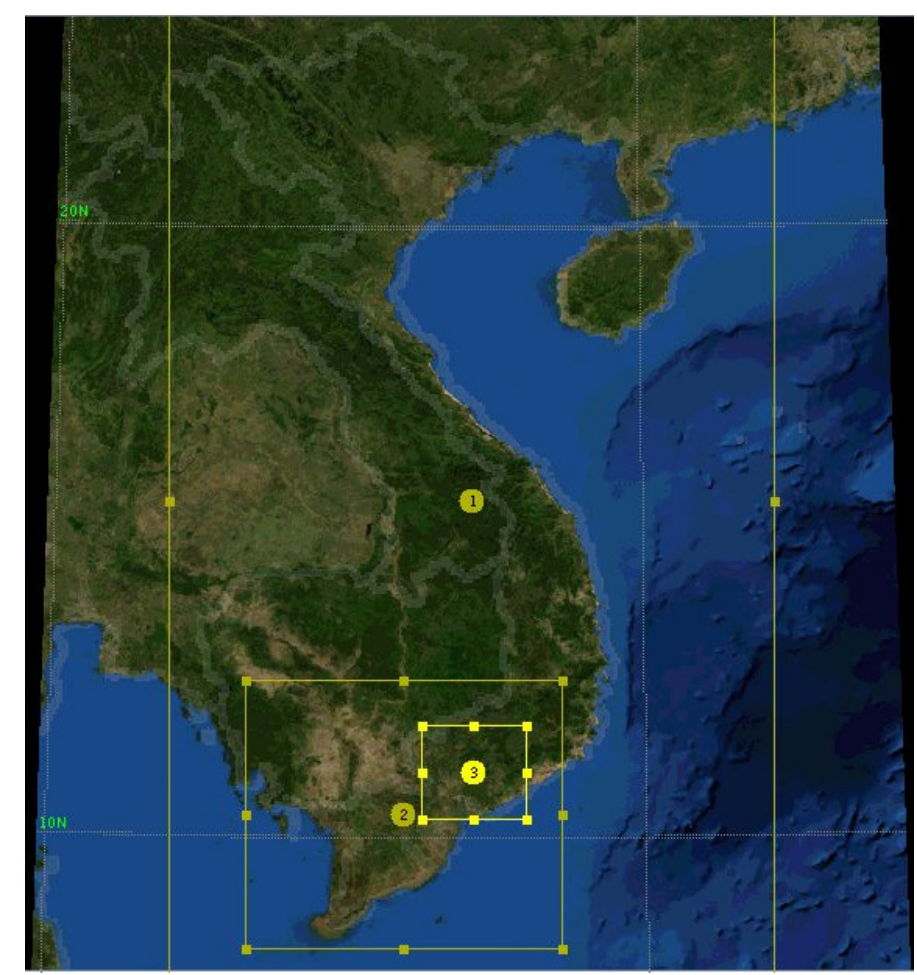

Hình 3. Miền lưới tính được sủ dụng trong nghiên cưu

Để phục vụ mô phỏng và kiểm nghiệm mô hình, nghiên cứu sẽ mô phỏng lại các trường khí tượng cho khu vực vào ngày 15 tháng 7 năm 2019, với số liệu đầu vào từ mô hình GFS (Global Forecasting System) là mô hình dự báo thời tiết toàn cầu được vận hành bởi Cơ quan Thời tiết Quốc gia Mỹ. Mô hình GFS chạy nghiệp vụ 4 lần trên ngày vào $0 \mathrm{~h}, 6 \mathrm{~h}, 12 \mathrm{~h}$ và $18 \mathrm{~h}$ với độ phân giải thời gian 16 ngày, trong đó 10 ngày đầu, độ phân giải không gian $0,25^{\circ}$ x $0,25^{\circ}$ kinh vĩ, 6 ngày sau là $1,0^{\circ} \times 1,0^{\circ}$ kinh vĩ. Các thông số chi tiết xem trong Bảng 2, Hình 3 .

\subsection{Mô hình lan truyền}

Mô hình toán được sử dụng có lưu ý tới địa hình do địa hình khu vực nghiên cứu khá phức tạp, không bằng phẳng. Công thức tính toán nồng độ chất ô nhiễm, áp dụng trong điều kiện ổn định hoặc không ổn định có dạng [4]:

$$
C_{T}\left\{x_{r}, y_{r}, z_{r}\right\}=f \cdot C_{c, s}\left\{x_{r}, y_{r}, z_{r}\right\}+(1-f) C_{c, s}\left\{x_{r}, y_{r}, z_{p}\right\}
$$

Trong đó $\mathrm{C}_{\mathrm{T}}\left\{\mathrm{x}_{\mathrm{r}}, \mathrm{y}_{\mathrm{r}}, \mathrm{z}_{\mathrm{r}}\right\}$ là tổng nồng độ; $\mathrm{C}_{\mathrm{c}, \mathrm{s}}$ $\left\{\mathrm{x}_{\mathrm{r}}, \mathrm{y}_{\mathrm{r}}, \mathrm{z}_{\mathrm{r}}\right\}$ là nồng độ đóng góp từ luồng khí theo phương ngang (các chỉ số $\mathrm{C}$ và $\mathrm{S}$ tương ứng với các trường hợp không ổn định và ổn định), $\mathrm{C}_{\mathrm{c}, \mathrm{s}}\left\{\mathrm{x}_{\mathrm{r}}, \mathrm{y}_{\mathrm{r}}, \mathrm{z}_{\mathrm{p}}\right\}$ là nồng độ đóng góp từ địa hình, $\mathrm{f}$ là hàm số trọng số, $\left\{\mathrm{x}_{\mathrm{r}}, \mathrm{y}_{\mathrm{r}}, \mathrm{z}_{\mathrm{r}}\right\}$ là biểu diễn tọa độ của điểm tiếp nhận (với $\mathrm{Z}_{\mathrm{r}}$ được xác định theo cao trình của ống khói), $\mathrm{z}_{\mathrm{p}}=\mathrm{Z}_{\mathrm{r}}-\mathrm{Z}_{\mathrm{t}}$ là chiều cao của điểm tiếp nhận so với địa hình và $\mathrm{Z}_{\mathrm{t}}$ là chiều cao địa hình tại điểm tiếp nhận [9-11]. Các công thức tính toán và bước thực hiện đã được mô tả trong [4]. Tuy nhiên, khác với trường hợp nguồn điểm, việc đánh giá hệ số phạm vi khuếch tán rối ngang và rối đứng trong trường hợp nguồn thể tích và nguồn đường có sự thay đổi so với nguồn thải điểm. Sự thay đổi này được lưu ý lần đầu tiên vào 1995 trong nghiên cứu [8] và được nhắc lại trong [9-11]. Với nguồn thể tích đánh giá các hệ số khuếch tán theo phương ngang, phương đứng được điều chỉnh như sau:

$$
\begin{aligned}
& \sigma_{y}^{2}=\sigma_{y l}^{2}+\sigma_{y o}^{2} \\
& \sigma_{z}^{2}=\sigma_{z l}^{2}+\sigma_{z o}^{2}
\end{aligned}
$$

Trong đó $\sigma_{\mathrm{yl}}(\mathrm{m})$ là phạm vi khuếch tán rối ngang của luồng khí trước khi lưu ý tới phạm vi khuếch tán ban đầu theo phương ngang; $\sigma_{\mathrm{y} 0}(\mathrm{~m})$ được định nghĩa là phạm vi khuếch tán ngang ban đầu $(\mathrm{m}) ; \sigma_{\mathrm{zl}}(\mathrm{m})$ là phạm vi khuếch tán rối 
đứng của luồng khí trước khi lưu ý tới phạm vi khuếch tán ban đầu theo phương đứng; $\sigma_{\mathrm{z} 0}$ được định nghĩa là phạm vi khuếch tán đứng ban đầu (m).

$$
\sigma_{y o}^{2}=w / 4.3
$$

Trong đó $\mathrm{w}(\mathrm{m})$ là kích thước của hình vuông đáy nguồn thải vùng.

$$
\sigma_{z o}^{2}=h / 2.15
$$

Trong đó $\mathrm{h}(\mathrm{m})$ là chiều cao của nguồn thể tích.

Các hệ số phạm vi khuếch tán rối ngang, rối đứng của luồng khí trước khi lưu ý tới phạm vi khuếch tán ban đầu theo phương ngang, phương đứng được tính toán giống như với nguồn điểm, được thể hiện trong các công thức

$$
\sigma_{y, z}^{2}=\sigma_{y a, z a}^{2}+\sigma_{b}^{2}
$$

Phạm vi khuếch tán tổng $\left(\sigma_{\mathrm{y}, \mathrm{z}}\right)$ theo phương ngang và phương đứng là sự kết hợp của phạm vi khuếch tán (đại diện bởi $\sigma_{\mathrm{ya}}, \sigma_{\mathrm{za}}$ ) do môi trường rối xung quanh và sự khuếch tán $\left(\sigma_{\mathrm{b}}\right)$ từ mức độ rối bởi sự nổi của luồng khí với điều kiệt vệt

\begin{tabular}{|c|c|c|c|}
\hline Các thông số miền tính & Miền tính 1 & Miền tính 2 & Miền tính 3 \\
\hline Phạm vi miền tính & Việt Nam & $\begin{array}{l}\text { Các tỉnh phía Nam (13 tỉnh } \\
\text { ĐBSCL + HCM, Đồng Nai, } \\
\text { Bình Dương, Tây Ninh, } \\
\text { Bình Phước, Bà Rịa Vũng } \\
\text { Tàu và một phần các tỉnh } \\
\text { Đak Nông, Lâm Đồng, Bình } \\
\text { Thuận }\end{array}$ & $\begin{array}{l}\text { Hồ Chí Minh, } \\
\text { Đồng Nai, } \\
\text { Bình Dương }\end{array}$ \\
\hline $\begin{array}{l}\text { Diện tích miền tính } \\
\left(\mathrm{km}^{2}\right)\end{array}$ & 2.181 .897 & 285.120 & 33.408 \\
\hline Hệ tọa độ mô hình & Lambert & Lambert & Lambert \\
\hline Tọa độ trung tâm & $\begin{array}{l}\text { Lat: } 15.532 \\
\text { Lon: } 107.078\end{array}$ & $\begin{array}{l}\text { Lat: } 10.38574 \\
\text { Lon: } 105.9714\end{array}$ & $\begin{array}{l}\text { Lat: } 11.07456 \\
\text { Lon: } \\
107.12684\end{array}$ \\
\hline Tọa độ miền tính & $\begin{array}{l}\text { Lat: } 6.622 \text { - } \\
24.24 \\
\text { Lon: } 101.729 \text { - } \\
112.626\end{array}$ & $\begin{array}{l}\text { Lat: } 8.09-12.468 \\
\text { Lon: } 103.2-108.416\end{array}$ & $\begin{array}{l}\text { Lat: } 10.198- \\
11.754 \\
\text { Lon: } 106.088 \\
-107.829\end{array}$ \\
\hline Kích thước ô lưới & $27 \mathrm{~km} \times 27 \mathrm{~km}$ & $9 \mathrm{~km} \times 9 \mathrm{~km}$ & $3 \mathrm{~km} \times 3 \mathrm{~km}$ \\
\hline Tổng số ô lưới & 2993 & 3520 & 3712 \\
\hline $\begin{array}{l}\text { Số ô lưới theo phương } \\
\text { ngang }\end{array}$ & 41 & 64 & 64 \\
\hline $\begin{array}{l}\text { Số ô lưới theo phương } \\
\text { dọc }\end{array}$ & 73 & 55 & 58 \\
\hline Phương pháp chạy & Lưới lồng & Lưới lồng & Lưới lồng \\
\hline
\end{tabular}
nâng cột khí bằng 0 .

Bảng 2. Thông số lưới tính

\subsection{Số liệu quan trắc}

Trong khuôn khổ thực hiện đề tài khoa học công nghệ cấp Bộ 2017 - 2020, đã thực hiện lấy mẫu và phân tích cho hai đợt, đợt 1 vào ngày 24/04/2019 và đợt 2 vào ngày 15/07/2019. Các mẫu không khí xung quanh được thu tại 12 điểm tại khu vực xung quanh mỏ đá huyện Bắc Tân Uyên, tỉnh Bình Dương (trên các tuyến đường vận chuyển và lân cận các khu vực moong, khu vực xay đá), xem Hình 4 và Bảng 6 . Các chỉ tiêu được chọn gồm: $\mathrm{SO}_{2}, \mathrm{NO}_{2}$ và bụi $\mathrm{PM}_{10}$. Trong nghiên cứu này, cùng với việc đo mới, đã kế thừa một số kết quả từ đề tài do nhóm tác giả thực hiện giai đoạn 2012 - 2014 [12], đặc biệt là kế thừa kết quả đo nồng độ TSP tại khu vực khai thác đá. Kết quả đo đạc được sử dụng để kiểm định kết quả chạy mô hình. 


\section{BÀI BÁO KHOA HỌC}

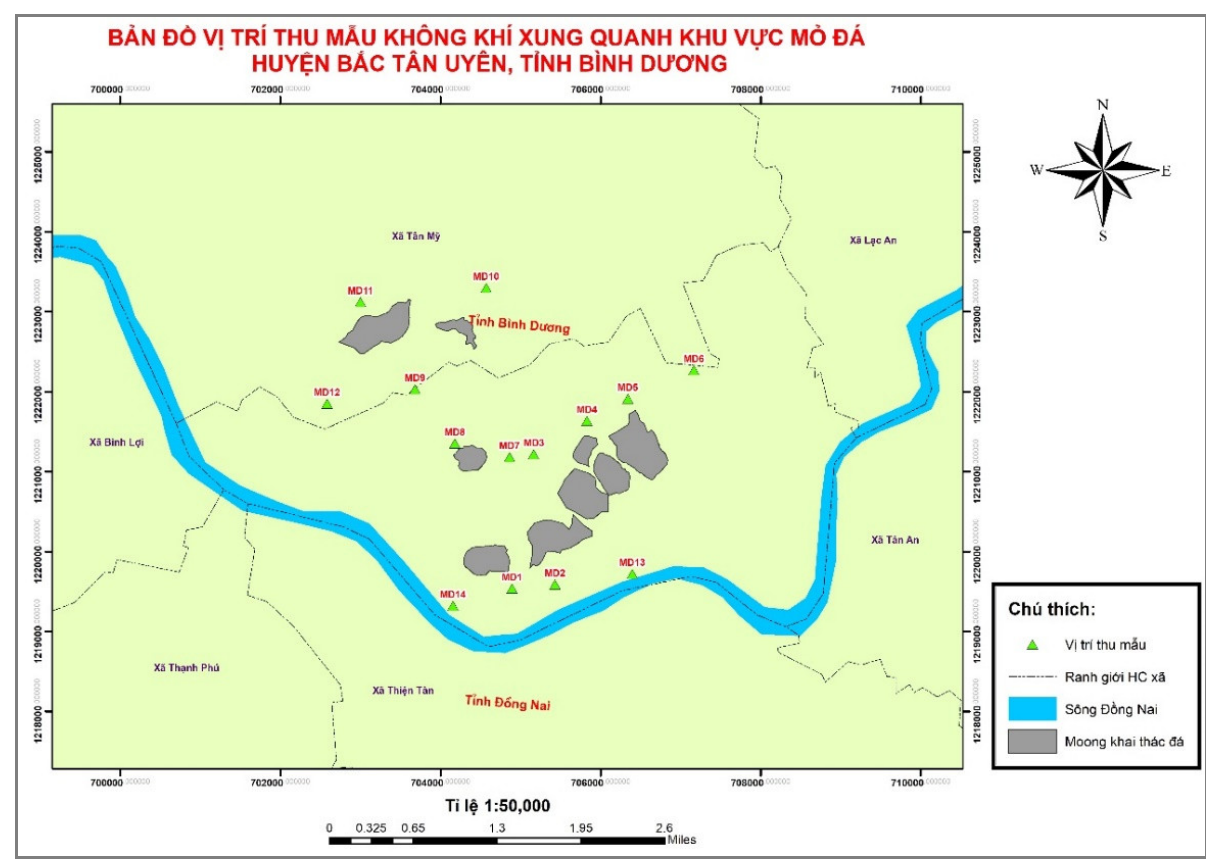

Hình 4. Bản đồ vị trí lấy mẫu chất lượng không khỉ khu vực xung quanh mỏ đá.

\subsection{Dũ liệu địa hình}

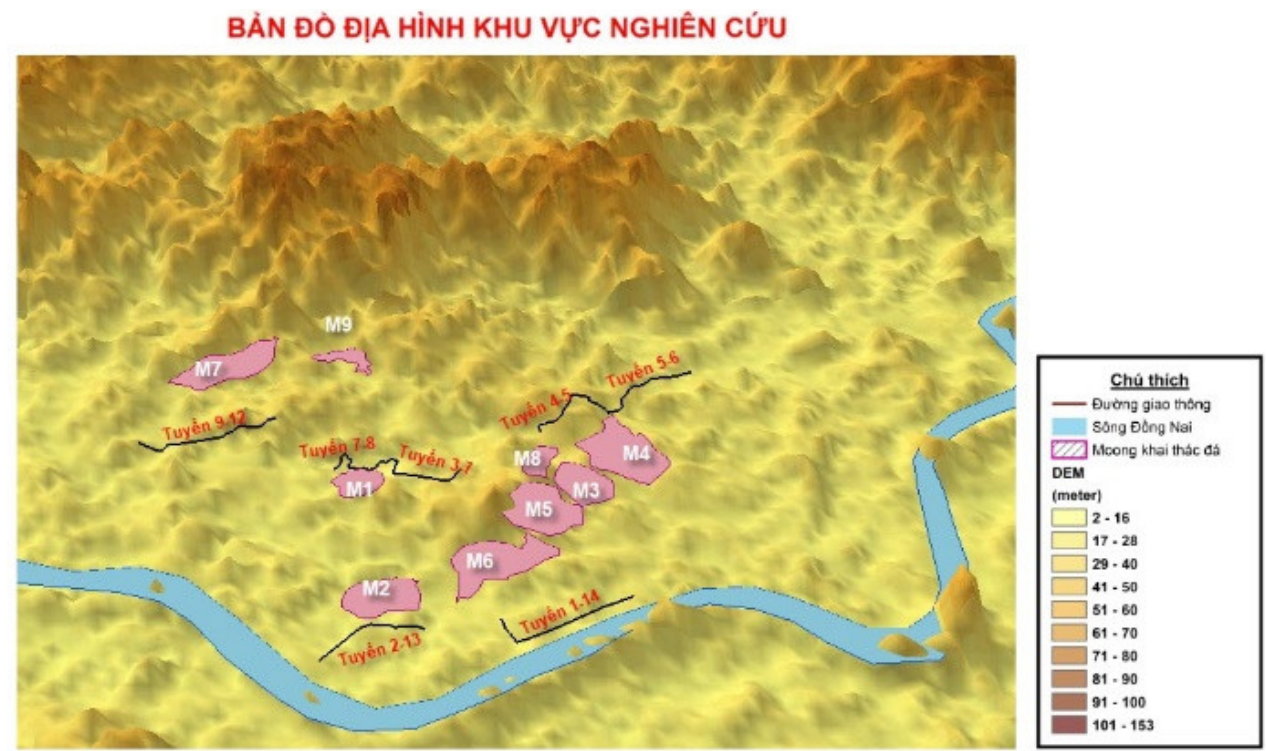

Hình 5. Bản đồ địa hình được sử dụng trong nghiên cứu.

Địa hình có ảnh hưởng đến tốc độ phát tán chất ô nhiễm do vậy đây là khâu rất quan trọng, dữ liệu địa hình và cao trình khu vực nghiên cứu được thể hiện trên các Hình 5. Thuật toán tính cho nghiên cứu này, được thực hiện tương ứng với phương pháp được $\mathrm{EPA}$ hướng dẫn trong [8]. Mỗi nguồn thể tích được phủ bởi lưới tính có kích thước tùy theo độ lớn của nguồn. Trên Hình 6 thể hiện lưới phủ lên từng moong đá, kích thước mỗi ô lưới là $80 \mathrm{~m}$ x $80 \mathrm{~m}$. Thuật toán được viết sẽ đánh số các ô lưới có giao với moong đá. Nguồn đường trong nghiên cứu này cũng được chia thành các ô vuông kích thước $30 \mathrm{~m}$ x $30 \mathrm{~m}$. Số lượng ô vuông sẽ phụ thuộc vào chiều dài của đoạn đường. Thông số phát thải được phân về cho các ô vuông có giao với lưới phủ theo tỷ lệ thích hợp. 

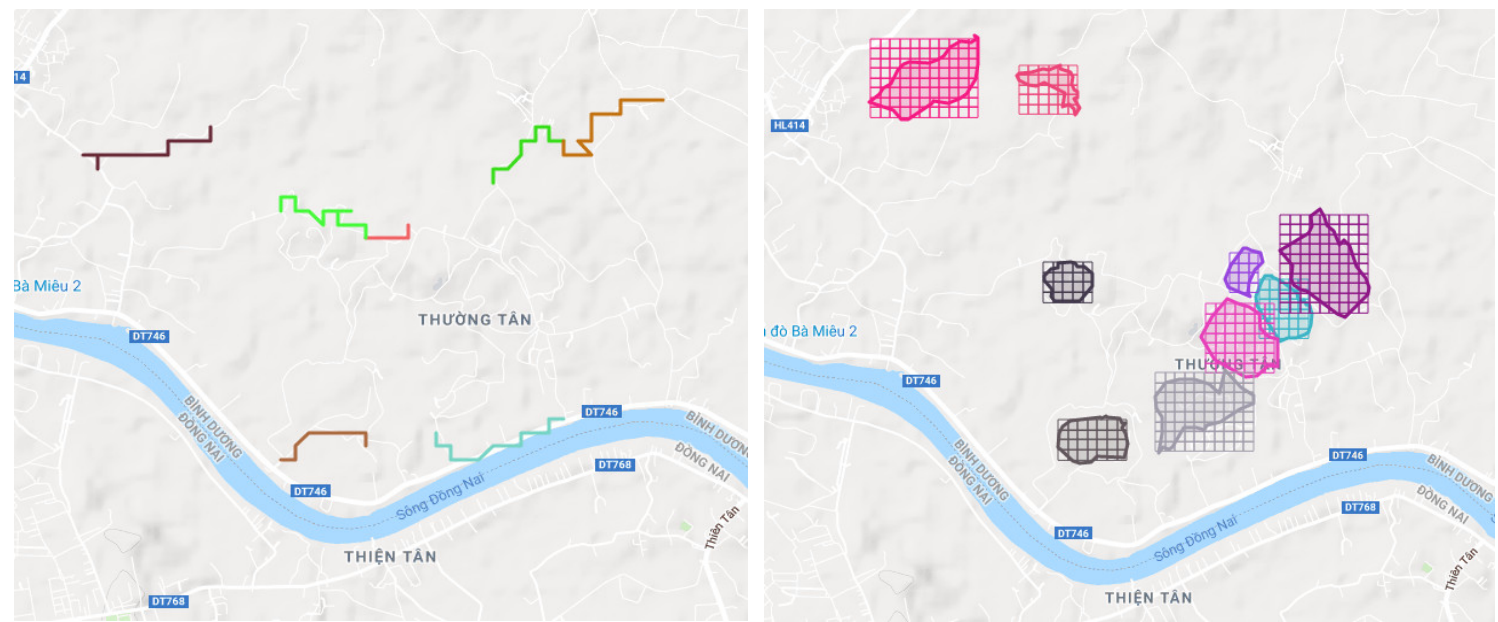

Hình 6. Các trục đường và moong khai thác đá đurợc xủ lý

\subsection{Xây dụng kịch bản tính toán}

Trong nghiên cứu này thực hiện 3 kịch bản với mục đích đánh giá sự lan truyền ô nhiễm từ mỗi loại hình nguồn và ô nhiễm tổng hợp. Kịch bản 1 chỉ xem xét nguồn đường, kịch bản 2 chỉ xem xét nguồn vùng và kịch bản 3 tổng hợp giữa nguồn đường và nguồn vùng. Chất ô nhiễm được chọn cho nghiên cứu này là $\mathrm{NO}_{2}, \mathrm{SO}_{2}$, bụi $\mathrm{PM}_{10}$ (Particulate Matter - hạt bụi lơ lửng đường kính nhỏ hơn 10 micromet). Kịch bản được thực hiện với 7 đường (Bảng 3 ) và nguồn thể tích 9 moong khai thác đá (Bảng 4), thời điểm tính toán được lựa chọn trùng với thời điểm lấy mẫu, phân tích chất lượng không khí, cụ thể là vào lúc 15/07/2019 vào lúc 9 giờ sáng. Sự lựa chọn này được giải thích để sử dụng kết quả đo diễn ra cùng thời điểm.

\subsection{Tiêu chí đánh giá}

Chỉ số đánh giá mức độ tương quan giữa kết quả tính toán và kết quả đo đạc, được xác định

theo các công thức sau:

$$
N A S H=1-\frac{\sum_{i=1}^{n}\left(C_{S i m}-C_{O b s}\right)^{2}}{\sum_{i=1}^{n}\left(C_{O b s}-C_{T B}\right)^{2}}
$$

Trong đó $\mathrm{C}_{\text {sim }}$ là nồng độ thông số ô nhiễm tính toán từ mô hình $\left(\mu \mathrm{g} / \mathrm{m}^{3}\right)$; Cobs là nồng độ thông số ô nhiễm từ thực đo $\left(\mu \mathrm{g} / \mathrm{m}^{3}\right) ; \mathrm{C}_{\mathrm{TB}}$ là nồng độ thông số ô nhiễm thực đo trung bình $\left(\mu \mathrm{g} / \mathrm{m}^{3}\right)$.

\section{Kết quả và thảo luận}

\subsection{Tính toán phát thải}

Nhóm nghiên cứu thực hiện tính toán phát thải ô nhiễm không khí cho 2 trường hợp: nguồn đường (Line Source); nguồn vùng (Volume Source) và nguồn thải kết hợp (Line - Volume Source) theo công thức trong mục 3.1. Kết quả tính toán được thể hiện trên các Bảng 3 và Bảng 4.

Bảng 3. Kết quả tính toán phát thải tù̀ nguồn đường

\begin{tabular}{lcccc}
\hline \multirow{2}{*}{ Tuyến đường } & Chiều dài & \multicolumn{3}{c}{ Công suất nguồn thải } \\
\cline { 3 - 5 } & $(\mathrm{km})$ & $\mathrm{SO}_{2}(\mathrm{mg} / \mathrm{s})$ & $\mathrm{NO}_{2}(\mathrm{mg} / \mathrm{s})$ & $\mathrm{PM}_{10}(\mathrm{mg} / \mathrm{s})$ \\
\hline Tuyến đường 9-12 & 1,29 & 51.988 & 548.910 & $6.573,209$ \\
Tuyến đường 3-7 & 0,37 & 0,149 & 1,244 & 0,292 \\
Tuyến đường 7-8 & 1,25 & 0,564 & 4,280 & 1,399 \\
Tuyến đường 4-5 & 0,91 & 0,136 & 0,226 & 0,905 \\
Tuyến đường 6-5 & 1,14 & 0,342 & 0,570 & 2,282 \\
Tuyến đường 13-2 & 1,21 & 81,510 & 847,572 & $10.038,429$ \\
Tuyến đường 14-1 & 0,89 & 125.602 & $1.319,057$ & $15.447,928$ \\
\hline
\end{tabular}


Bảng 4. Kết quả tính toán phát thải tù̀ nguồn vùng (moong khai thác đá)

\begin{tabular}{llc}
\hline \multirow{2}{*}{ Nguồn vùng } & \multicolumn{1}{c}{ Địa điểm } & Công suất nguồn thải \\
\cline { 3 - 3 } Moong số 1 - M1 & Thường Tân & PM $_{10}(\mathrm{mg} / \mathrm{s})$ \\
Moong số 2 - M2 & Thường Tân & $6.461,950$ \\
Moong số 3 - M3 & Thường Tân & $7.033,142$ \\
Moong số 4 - M4 & Thường Tân & $8.261,651$ \\
Moong số 5 - M5 & Thường Tân & $4.294,566$ \\
Moong số 6 - M6 & Thường Tân & $7.237,229$ \\
Moong số 7 - M7 & Tân Mỹ & $6.913,656$ \\
Moong số 8 - M8 & Thường Tân & $5.890,740$ \\
Moong số 9 - M9 & Tân Mỹ & $4.416,387$ \\
\hline
\end{tabular}

\subsection{Tính toán các thông số khí tượng lớp} biên

Kết quả chạy mô hình khí tượng dựa trên cơ sở mục 2.3 được xuất ra vào thời điểm $9 \mathrm{~h}$ sáng ngày 15/07/2019 tại khu vực tính toán cho phép xác định các yếu tố khí tượng cần thiết cho tính toán ô nhiễm không khí. Các kết quả tính toán được thể hiện trong Bảng 5 .

Bảng 5. Các thông số khí tượng lớp biên khi quyển được sủ dụng

\begin{tabular}{lc}
\hline \multicolumn{1}{c}{ Các thông số lớp biên khí quyển } & Giá trị \\
\hline Vận tốc gió ở độ cao tham chiếu $(\mathrm{m} / \mathrm{s})$ & 4,17 \\
Hướng gió $\left({ }^{\circ}\right.$ Degrees) & 266,1 \\
Nhiệt độ $\left({ }^{\circ} \mathrm{K}\right)$ & 304 \\
Độ dài Monin-Obukhov $(\mathrm{m})$ & $-56,4$ \\
Chiều cao lớp hòa trộn đối lưu PBL (m) & 1.097 \\
Vận tốc ma sát bề mặt $\left(\mathrm{m} \cdot \mathrm{s}^{-1}\right)$ & 0,49 \\
Vận tốc đối lưu $\left(\mathrm{m} \cdot \mathrm{s}^{-1}\right)$ & 1,788 \\
\hline
\end{tabular}

Bộ thông số lớp biên khí tượng từ Bảng 5 được đưa vào các công thức toán trong mục 3.3 để tính toán. Để thực hiện phần tính toán, nhóm tác giả đã viết code bằng ngôn ngữ $\mathrm{C} \#$ đặt tên là EnvimAP để tự động hóa quá trình tính toán nguồn thải - điểm tiếp nhận. Kết quả tính toán tại nút lưới được chuyển qua ArcGIS để tiếp tục xử lý và vẽ các đường đồng mức. Trong nghiên cứu này, chọn mức độ cao $\mathrm{z}=1,5 \mathrm{~m}$ để tính toán xuất kết quả. Điều này là do nhóm nghiên cứu chọn thời điểm lấy mẫu tại độ cao này để kiểm định kết quả chạy mô hình.

\subsection{Kết quả tính toán ô nhiễm không khí}

Kịch bản 1 với trường hợp nguồn đường (Line Source), kết quả các thông số $\mathrm{SO}_{2}, \mathrm{NO}_{2}$, bụi $\mathrm{PM}_{10}$ được thể hiện trên Hình 7-9. Kết quả tính toán cho thấy mối tương quan giữa nồng độ và các yếu tố khí tượng được thể hiện khá rõ nét, sự pha loãng diễn ra khá tốt. Giá trị nồng độ $\mathrm{SO}_{2}$ dao động từ $26,8-45,5 \mu \mathrm{g} / \mathrm{m}^{3}$; giá trị nồng độ $\mathrm{NO}_{2}$ dao động từ $0-35,8 \mu \mathrm{g} / \mathrm{m}^{3}$ và giá trị bụi $\mathrm{PM}_{10}$ dao động từ 227,7 - 476,9 $\mu \mathrm{g} / \mathrm{m}^{3}$. Nồng độ $\mathrm{SO}_{2}, \mathrm{NO}_{2}$ đều thấp hơn rất nhiều lần giới hạn cho phép trung bình 1 giờ của QCVN 05:2013/ BTNMT (350 và $200 \mu \mathrm{g} / \mathrm{m}^{3}$ ); nồng độ bụi PM10 phân bố ở các tuyến đường giao thông đều thấp hơn nhiều so với khu vực moong khai thác đá. Điều này chứng tỏ, hoạt động giao thông (chủ yếu là vận chuyển đá) trong khu vực không phải là nguyên nhân chính gây ảnh hưởng đến chất lượng không khí xung quanh. 
BÀI BÁO KHOA HỌC

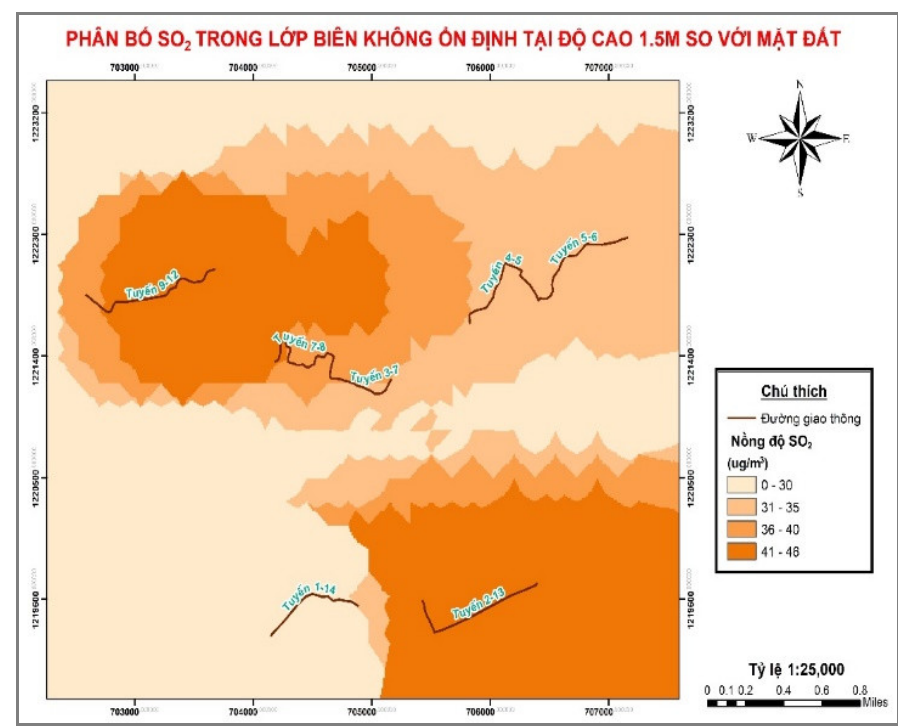

Hình 7. Phân bố ô nhiễm $\mathrm{SO}_{2}$ lúc 9 giờ sáng, kịch bản 1

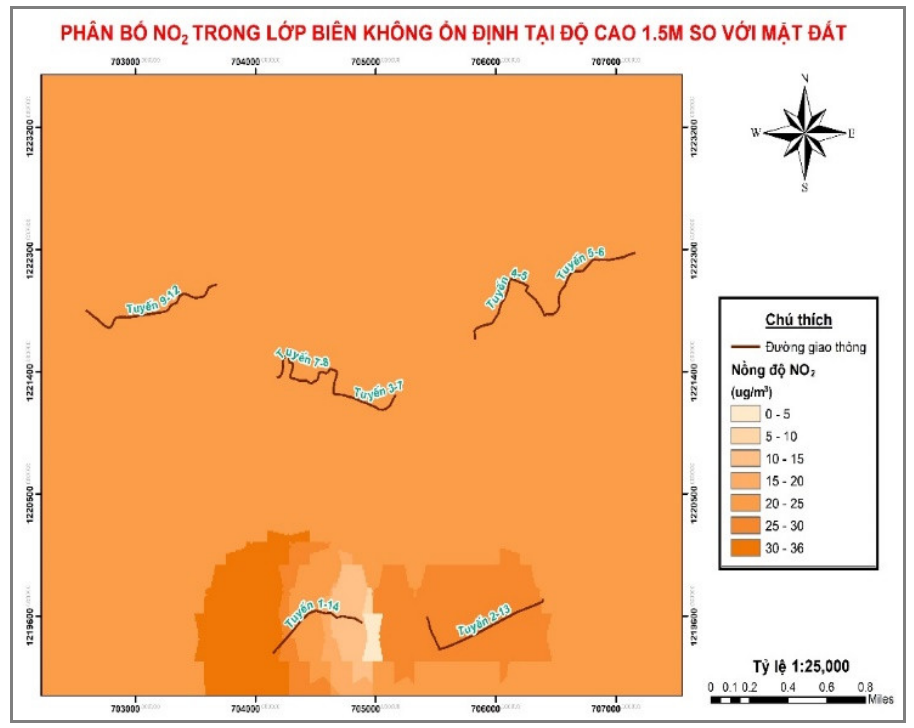

Hình 8. Phân bố ô nhiễm $\mathrm{NO}_{2}$ lúc 9 giờ sáng, kịch bản 1

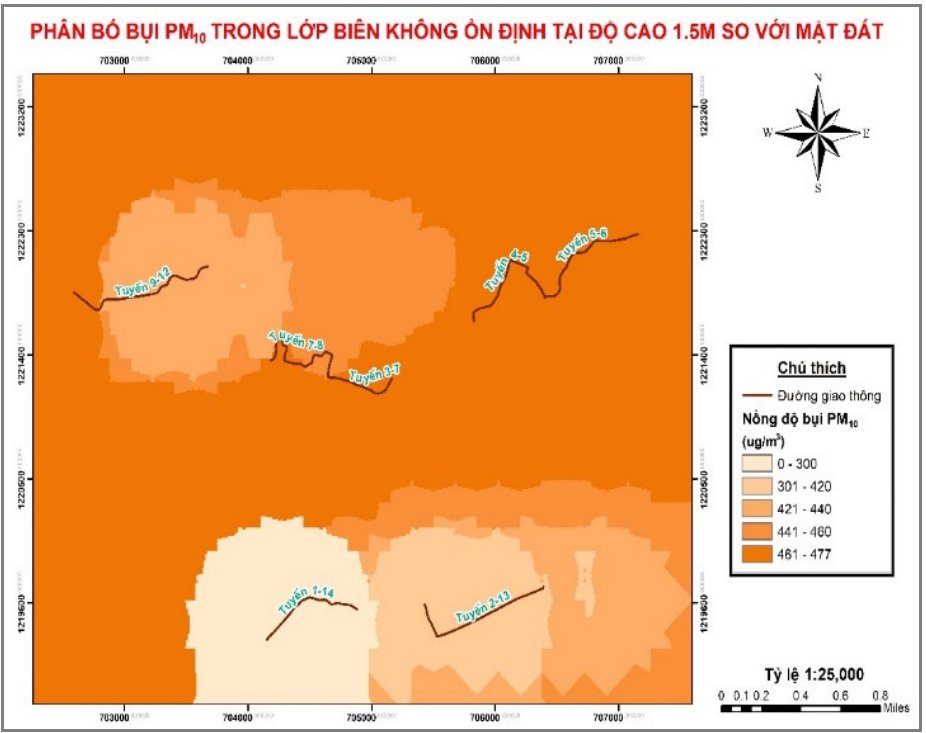

Hình 9. Phân bố ô nhiễm bụi PMIo lúc 9 giờ sáng, kịch bản 1 


\section{BÀI BÁO KHOA HỌC}

Kịch bản 2 nguồn vùng (Volume Source) và kịch bản 3 với nguồn thải kết hợp (Line - Volume Source), kết quả tính toán thông số bụi $\mathrm{PM}_{10}$ được thể hiện trên các Hình 10-11. Cụ thể, trong kịch bản 2 , nồng độ bụi $\mathrm{PM}_{10}$ dao động từ 0 $521,8 \mu \mathrm{g} / \mathrm{m}^{3}$ và kịch bản 3 dao động từ $0-526,6$ $\mu \mathrm{g} / \mathrm{m}^{3}$. Như vậy, trường hợp tính cho nguồn vùng và nguồn thải kết hợp, nồng độ bụi $\mathrm{PM}_{10}$ không có nhiều sự khác biệt cho thấy hoạt động khai thác đá, xay đá tại các moong là nguyên nhân chủ yếu phát tán bụi $\mathrm{PM}_{10}$.

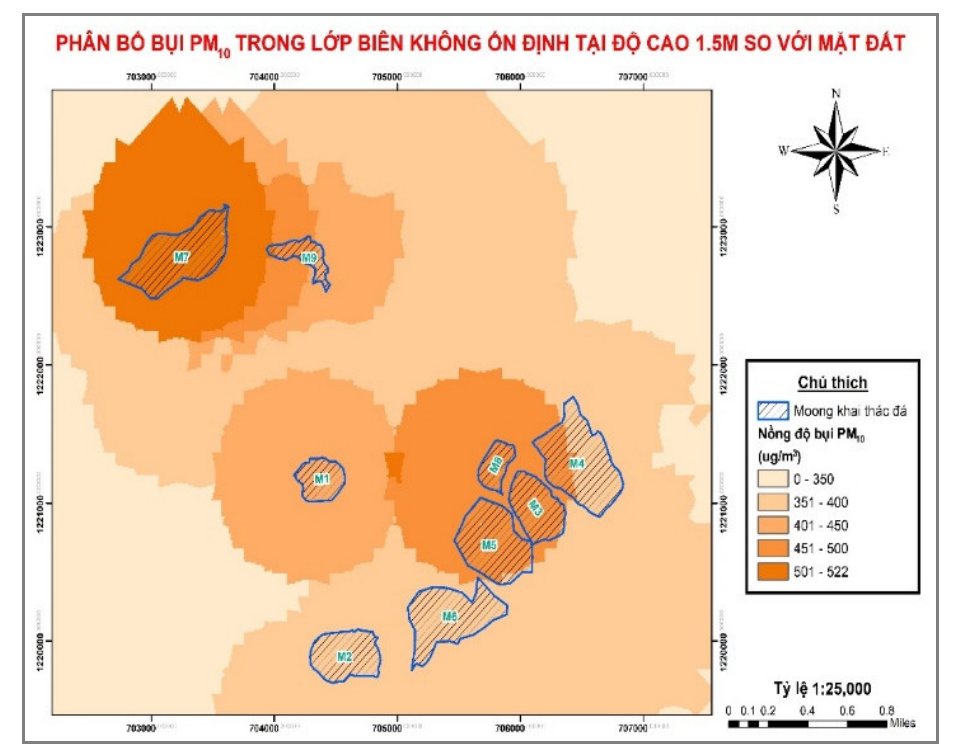

Hình 10. Phân bố ô nhiễm bụi PM10 lúc 9 giờ sáng, kịch bản 2 (chỉ có nguồn vùng)

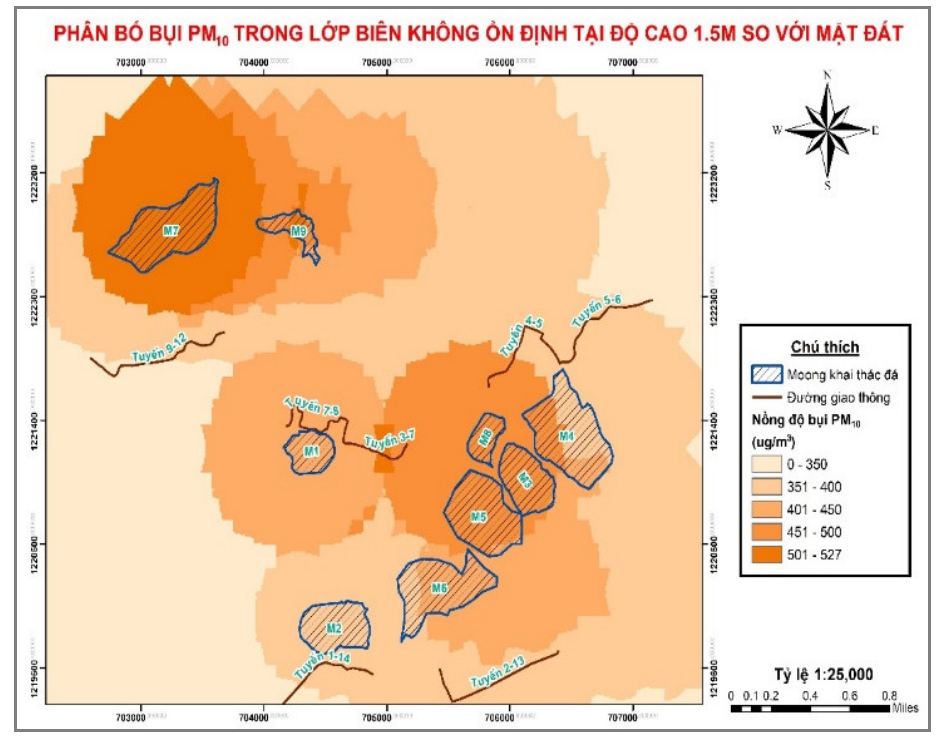

Hình 11. Phân bố ô nhiễm bụi PM10 lúc 9 giờ sáng, kịch bản 3 (cộng hưởng nguồn vùng và nguồn đường)

\subsection{Thảo luận}

Để kiểm định mức độ tin cậy kết quả tính theo mô hình, đã thực hiện lấy mẫu thực địa và phân tích chất lượng không khí xung quanh tại 12 vị trí trong khu vực (Hình 4) ngày 15/07/2019, lúc 9 giờ. Kết quả kiểm định $\mathrm{SO}_{2}$ tính theo mô hình và đo thực tế được thể hiện trên Hình 11 với chỉ số NASH trong trường hợp
$\mathrm{SO}_{2}$ là 0,71 . Kết quả kiểm định chỉ tiêu $\mathrm{NO}_{2}$ tính theo mô hình và kết quả đo thực tế được thể hiện trên Hình 12 với chỉ số Nash bằng 0,70 . Tương tự với thông số $\mathrm{PM}_{10}$ với chỉ số Nash bằng 0,71 và thể hiện trên Hình 13. Bảng 6 thể hiện kết quả so sánh kết quả nồng độ $\mathrm{SO}_{2}, \mathrm{NO}_{2}$ và chỉ số Nash theo kịch bản 1 . 


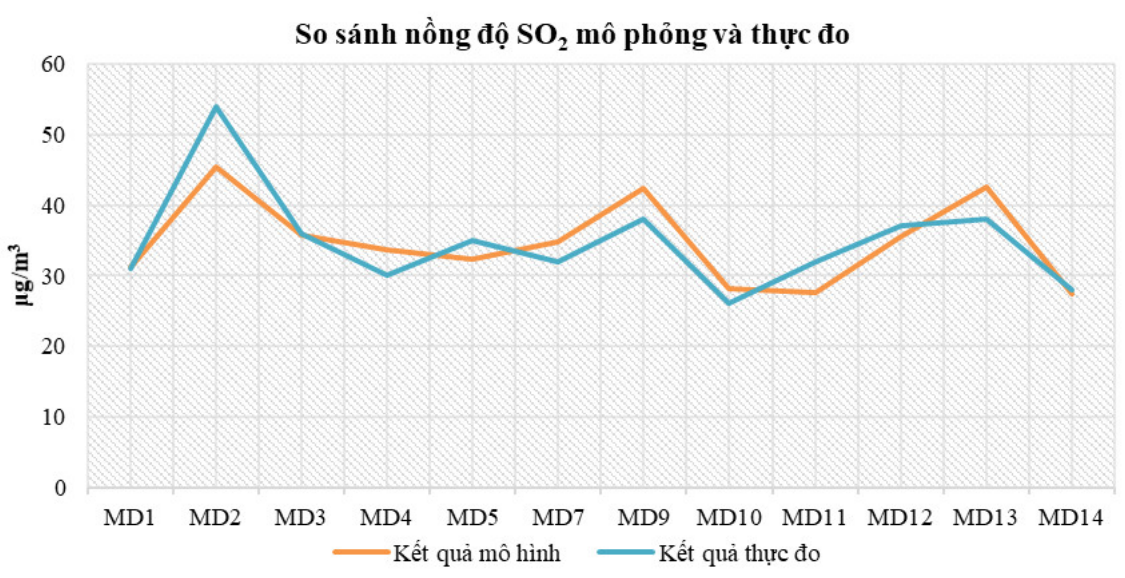

Hình 12. Biểu đồ tương quan nồng độ $\mathrm{SO}_{2}$ theo kịch bản 1

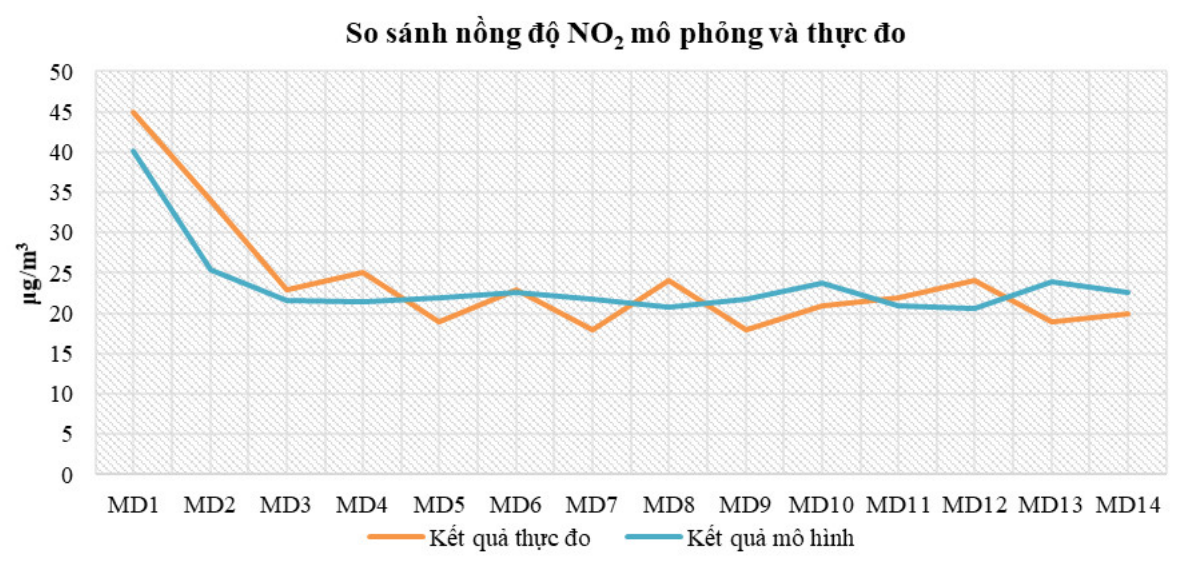

Hình 13. Biểu đồ tương quan nồng độ $\mathrm{NO}_{2}$ theo kịch bản 1

Bảng 6. So sánh kết quả nồng độ $\mathrm{SO}_{2}, \mathrm{NO}_{2}$ và chỉ số Nash theo kịch bản 1

\begin{tabular}{|c|c|c|c|c|c|c|c|}
\hline \multirow{2}{*}{ TT } & \multirow{2}{*}{ Vị trí } & \multicolumn{2}{|c|}{ Tọa độ } & \multicolumn{2}{|c|}{$\begin{array}{c}\text { Nồng độ } \mathrm{SO}_{2} \\
\left(\mu \mathrm{g} / \mathrm{m}^{3}\right)\end{array}$} & \multicolumn{2}{|c|}{$\begin{array}{c}\text { Nồng độ } \mathrm{NO}_{2} \\
\left(\mu \mathrm{g} / \mathrm{m}^{3}\right)\end{array}$} \\
\hline & & $X(m)$ & $Y(m)$ & $\begin{array}{l}\text { Kết quả } \\
\text { mô hình }\end{array}$ & $\begin{array}{l}\text { Kết quả } \\
\text { thực đo }\end{array}$ & $\begin{array}{l}\text { Kết quả } \\
\text { mô hình }\end{array}$ & $\begin{array}{l}\text { Kết quả } \\
\text { thực đo }\end{array}$ \\
\hline 1 & MD1 & 704894,62 & 1219538,86 & 31,164 & 31 & 40,171 & 45 \\
\hline 2 & MD2 & 705430,33 & 1219588,81 & 45,481 & 54 & 25,379 & 34 \\
\hline 3 & MD3 & 705163,46 & 1221216,87 & 35,784 & 36 & 21,538 & 23 \\
\hline 4 & MD4 & 705828,92 & 1221633,60 & 33,712 & 30 & 21,504 & 25 \\
\hline 5 & MD5 & 706338,73 & 1221912,36 & 32,369 & 35 & 21,907 & 19 \\
\hline 6 & MD7 & 704863,82 & 1221180,81 & 34,759 & 32 & 22,509 & 23 \\
\hline 7 & MD9 & 703682,36 & 1222031,28 & 42,381 & 38 & 21,716 & 18 \\
\hline 8 & MD10 & 704571,91 & 1223299,34 & 28,190 & 26 & 20,773 & 24 \\
\hline 9 & MD11 & 702999,95 & 1223121,18 & 27,651 & 32 & 21,762 & 18 \\
\hline 10 & MD12 & 702583,15 & 1221851,50 & 35,594 & 37 & 23,737 & 21 \\
\hline 11 & MD13 & 706395,65 & 1219721,82 & 42,593 & 38 & 20,963 & 22 \\
\hline 12 & MD14 & 704156,71 & 1219321,18 & 27,327 & 28 & 20,667 & 24 \\
\hline- & \multicolumn{3}{|c|}{ Kết quả chỉ số NASH } & \multicolumn{2}{|c|}{0,71} & \multicolumn{2}{|c|}{0,70} \\
\hline
\end{tabular}




\section{BÀI BÁO KHOA HỌC}

Kiểm định kịch bản 1 cho thấy kết quả tính từ mô hình và số liệu quan trắc thực tế có tương quan ở mức chấp nhận được. Sai số ở đây có thể giải thích điều này bởi kết quả mô hình chưa lưu ý tới nồng độ nền trong khu vực. Ngoài ra, một nguyên nhân nữa là sai số trong quá trình tiến hành lấy mẫu đo đạc và phân tích.

Kết quả kiểm định chỉ tiêu $\mathrm{PM}_{10}$ theo 3 kịch bản $1,2,3$ thể hiện trên Hình 14 - 16 và Bảng 7 . Cũng giống như trên, sai số ở đây được giải thích bởi chưa lưu ý tới nồng độ nền nền tại khu vực nghiên cứu.

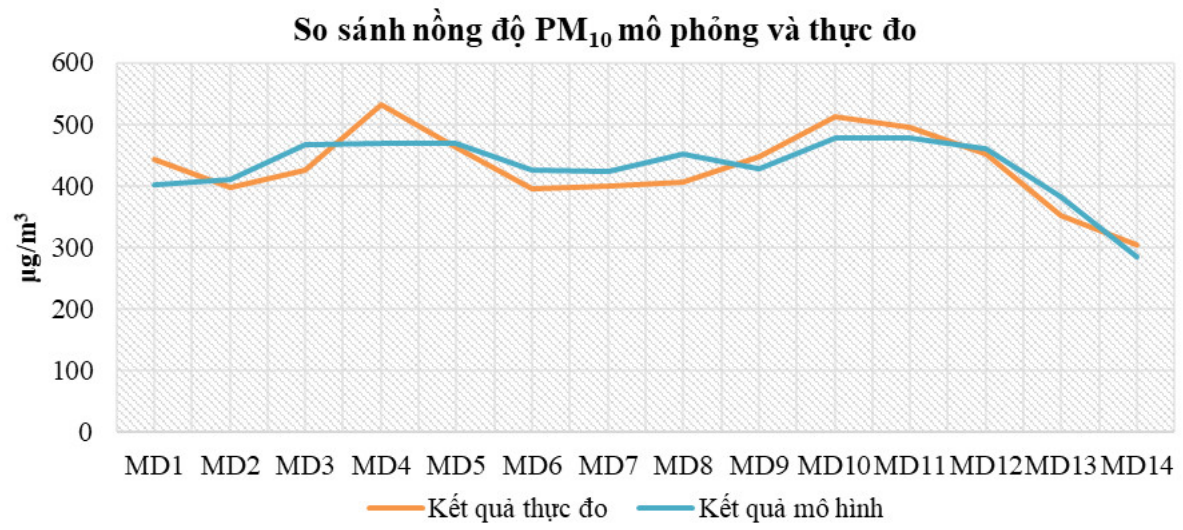

Hình 14. Biểu đồ tuoong quan nồng độ $P M_{10}$ theo kịch bản 1

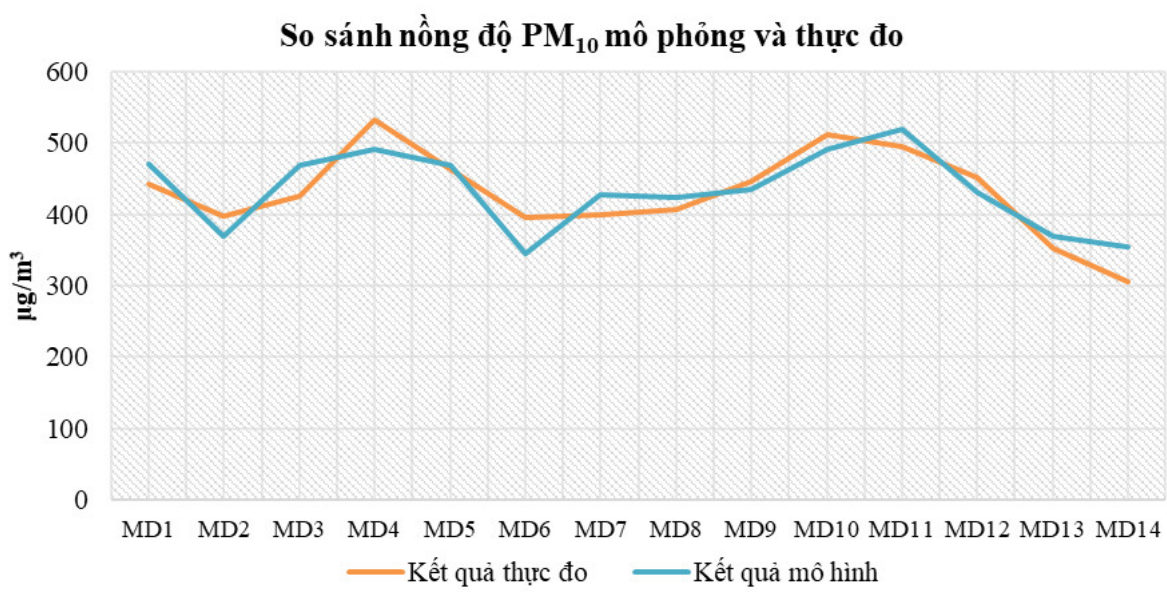

Hình 15. Biểu đồ tưong quan nồng độ PM $M_{10}$ theo kịch bản 2

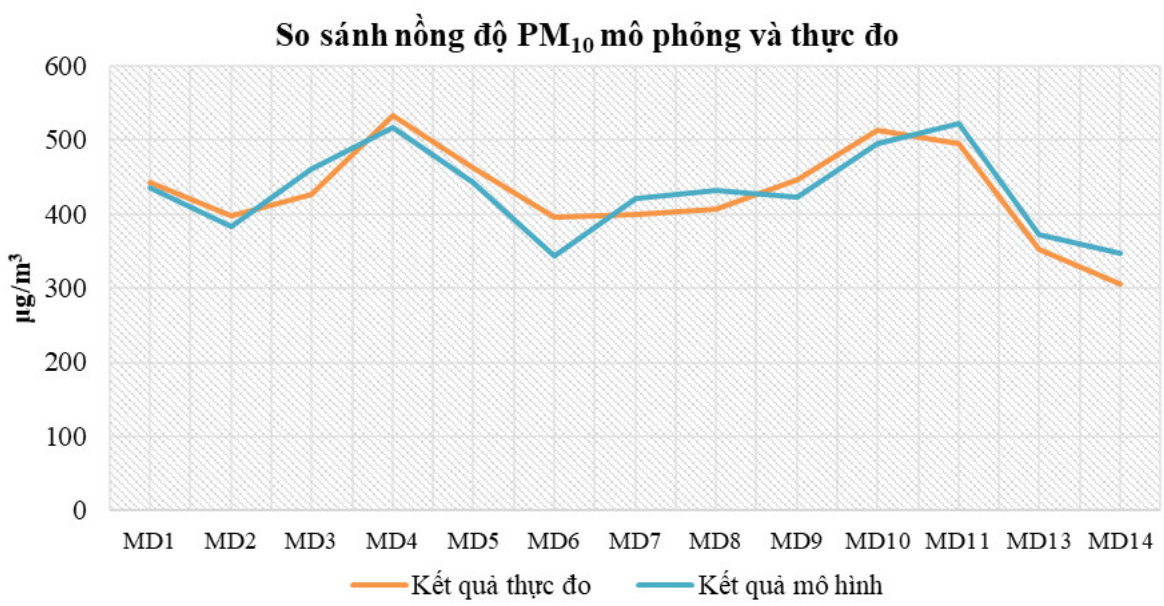

Hình 16. Biểu đồ tưong quan giũua nồng độ PMIo mô phỏng theo kịch bản 3 
Bảng 7. So sánh kết quả nồng độ $P M_{10}$ theo kịch bản 1, 2, 3 và chỉ số Nash

\begin{tabular}{|c|c|c|c|c|c|c|c|}
\hline \multirow[b]{2}{*}{ TT } & \multirow[b]{2}{*}{ Vị trí } & \multicolumn{2}{|c|}{$\begin{array}{c}\text { Nồng độ } \mathrm{PM}_{10}\left(\mu \mathrm{g} / \mathrm{m}^{3}\right) \\
\text { Kịch bản } 1\end{array}$} & \multicolumn{2}{|c|}{$\begin{array}{c}\text { Nồng độ } \mathrm{PM}_{10} \\
\left(\mu \mathrm{g} / \mathrm{m}^{3}\right) \\
\text { Kịch bản } 2 \\
\end{array}$} & \multicolumn{2}{|c|}{$\begin{array}{c}\text { Nồng độ } \mathrm{PM}_{10} \\
\left(\mu \mathrm{g} / \mathrm{m}^{3}\right) \\
\text { Kịch bản } 3\end{array}$} \\
\hline & & $\begin{array}{l}\text { Kết quả mô } \\
\text { hình }\end{array}$ & $\begin{array}{c}\text { Kết } \\
\text { quả } \\
\text { thực } \\
\text { đo }\end{array}$ & $\begin{array}{c}\text { Kết quả } \\
\text { mô } \\
\text { hình }\end{array}$ & $\begin{array}{c}\text { Kết } \\
\text { quả } \\
\text { thực đo }\end{array}$ & $\begin{array}{l}\text { Kết quả } \\
\text { mô hình }\end{array}$ & $\begin{array}{c}\text { Kết } \\
\text { quả } \\
\text { thực } \\
\text { đo }\end{array}$ \\
\hline 1 & MD1 & 402,303 & 442 & 471,161 & 442 & 434,451 & 442 \\
\hline 2 & MD2 & 409,589 & 398 & 369,387 & 398 & 382,998 & 398 \\
\hline 3 & MD3 & 467,135 & 426 & 468,390 & 426 & 460,178 & 426 \\
\hline 4 & MD4 & 469,194 & 532 & 490,638 & 532 & 516,275 & 532 \\
\hline 5 & MD5 & 468,947 & 463 & 469,310 & 463 & 442,675 & 463 \\
\hline 6 & MD7 & 424,923 & 395 & 345,408 & 395 & 344,258 & 395 \\
\hline 7 & MD9 & 422,638 & 400 & 426,427 & 400 & 421,757 & 400 \\
\hline 8 & MD10 & 451,931 & 407 & 424,155 & 407 & 432,443 & 407 \\
\hline 9 & MD11 & 427,503 & 447 & 434,875 & 447 & 422,262 & 447 \\
\hline 10 & MD12 & 476,596 & 512 & 490,583 & 512 & 494,051 & 512 \\
\hline 11 & MD13 & 476,960 & 495 & 518,277 & 495 & 522,276 & 495 \\
\hline 12 & MD14 & 460,286 & 452 & 430,612 & 452 & 371,949 & 352 \\
\hline - & $\begin{array}{l}\text { Kết quả chỉ } \\
\text { số NASH }\end{array}$ & \multicolumn{2}{|c|}{0,71} & \multicolumn{2}{|c|}{0,73} & \multicolumn{2}{|c|}{0,80} \\
\hline
\end{tabular}

\section{Kết luận}

Nghiên cứu được thực hiện với mục tiêu xây dựng phương pháp tính lan truyền ô nhiễm không khí cho trường hợp nguồn đường và nguồn thể tích có lưu ý tới địa hình phức tạp với các yếu tố khí tượng được lấy từ kết quả chạy WRF. Kết quả tính toán được thực hiện cho chất ô nhiễm là $\mathrm{SO}_{2}, \mathrm{NO}_{2}$, bụi $\mathrm{PM}_{10}$ với 3 kịch bản khác nhau. Kết quả mô phỏng được kiểm định dựa trên số liệu quan trắc cho thấy kết quả mô hình hóa có độ tin cậy chấp nhận được. Các nghiên cứu trong tương lai sẽ dựa trên số liệu thực đo để tiếp tục kiểm định các kết quả mô hình hóa là bước đi quan trọng để ứng dụng mô hình cho các dự án của đất nước.

Lời cảm ơn: Nghiên cứu này được tài trợ một phần tù đề tài khoa học và công nghệ cấp Bộ 2017 - 2019 theo quyết định số 1219/QĐ-BTNMT ngày 19/5/2017. Nhóm tác giả xin bày tỏ sư cảm on trân thành tới Bộ và Ban chủ nhiệm churong trình. Nhóm tác giả cũng bày tỏ sự cám ơn tới Phòng Thi nghiệm Trọng điểm Quốc gia Điều khiển số và Kỹ thuật hệ thống, Truờng Đại học Bách Khoa - Đại hoc Quốc gia Tp. Hồ Chí Minh đã tạo điều kiện cho nghiên cứu này được thực hiện.

\section{Tài liệu tham khảo}

1. Phan Hoài Trung, An Quốc Khánh (1988), Sư dụng mô hình Gauss trong công tác kiểm soát nguồn thải chất bẩn vào không khi (nguồn đơn). Tạp chí Khí tượng Thủy văn, 655, 15-21.

2. Phan Hoài Trung, An Quốc Khánh (1989), Bài toán tính truờng ô nhiễm tì̀ N nguồn thải và một vài khía cạnh của vấn đề chuẩn nguồn thải. Tạp chí Khí tượng Thủy văn, 656, 9-13.

3. Trần Ngọc Chấn (2001), Ô nhiếm không khí và xủ lý khí thải - Tập 1: Ô nhiếm không khí và tính toán khuếch tán chất ô nhiếm. Nxb Khoa học và kỹ Thuật, Hà Nội.

4. Bùi Tá Long, Nguyễn Châu Mỹ Duyên (2019), Mô hình hóa ô nhiễm không khí trong điều kiện 


\section{BÀI BÁO KHOA HỌC}

địa hình phức tạp - trương hơp nguồn thải điểm. Tạp chí Khí tượng Thủy văn, 700, 34-45.

5. Teggi, S., Costanzini, S., Ghermandi, G., Malagoli, C., Vinceti, M., (2018), GIS-based atmospheric dispersion model for pollutants emitted by complex source areas. Science of the Total Environment, 610-611, 175-190.

6. Gulliver, J., Briggs, D., (2011), STEMS-Air: A simple GIS-based air pollution dispersion model for city-wide exposure assessment. Science of the Total Environment, 409, 2419-2429.

7. Huertas, J.I., Huertas, M.E., Cervantes, G., Díaz, J., (2014), Assessment of the natural sources of particulate matter on the opencast mines air quality. Science of the Total Environment, 493, 1047-1055.

8. Environmental Protection Agency (1995), User's Guide for the Industrial Source Complex (ISC3) Dispersion Model (revised). Volume II - Description of Model Algorithms. EPA-454/b-950036.

9. Environmental Protection Agency (2004a), AERMOD deposition algorithms - science document (revised draft). Technical Report. U.S. Environmental Protection Agency.

10. Environmental Protection Agency (2004b), User's Guide for the AMS/EPA Regulatory Model - AERMOD. Technical Report EPA-454/B-03-001. U.S. Environmental Protection Agency.

11. Environmental Protection Agency (2016), Technology Transfer Network Support Center for Regulatory Atmospheric Modeling - Preferred/Recommended models. Online aviliable 27 April 2017.

12. Bùi Tá Long (2014), Đánh giá, dụ báo tác động ô nhiễm môi trương do bụi tại khu vục khai thác đá tập trung tại xã Thuờng Tân, Tân Mỹ và đề xuất giải pháp quản lý. Báo cáo kết quả tổng hợp đề tài nghiên cứu khoa học.

13. Belalcazar, L., Fuhrer, O., Ho. D., Zarate, E., Clappier, A., (2009), Estimation of road traffic emission factors from a long term tracer study in Ho Chi Minh City (Vietnam). Atmospheric Environment, 43, 5830-5837.

14. DOSTE (Department of Science, Technology and Environment of HO Chi Minh city) (2001), Urban transport energy demand and emission analysis - Case study of HCM city. No. 1 (phase II).

15. Bang Quoc Ho (2017), Modeling PM10 in Ho Chi Minh City, Vietnam and evaluation of its impact on human health. Sustainable Environment Research, 27, 95-102.

16. Skamarock, W.C., Klemp, J.B., Dudhia, J., Gill, D.O., Barker, D., Duda, M.G., .. Powers, J.G., (2008), A Description of the Advanced Research WRF Version 3 (No. NCAR/TN-475+STR). University Corporation for Atmospheric Research. doi:10.5065/D68S4MVH.

17. Janjic, Z.I., (2003), A nonhydrostatic model based on a new approach. Meteorol. Atmos. Phys., 82, 271-285.

18. Knievel, J., (2005). The WRF Model. National Center for Atmospheric Research Boulder, CO, USA. 


\title{
MODELING AIR POLLUTION FOR LINE AND VOLUME EMISSIONS - A CASE STUDY IN BINH DUONG QUARRY \\ Bui Ta Long' ${ }^{1}$, Nguyen Hoang Phong ${ }^{1}$, Nguyen Chau My Duyen ${ }^{1}$ \\ ${ }^{1}$ Hochiminh city University of Technology
}

\begin{abstract}
Emissions from open pit mining are the main causes of environmental pollution from line and volume sources. Environmental modeling is an indispensable tool for assessing the extent and level of influence of this type of activity. Over the years, many studies have been conducted based on various methods of mathematical modeling, especially the EPA (USA) proposed calculation methods to pay attention to complex terrain and meteorological changes in the boundary layer of the air layer. This article, based on the method combined an approach integrating mathematical models, GIS and WRF for calculating air pollution from volume and line sources during mining from a stone quarry in Binh Duong. The results are verified by using measured data showing the reliability of the proposed model.
\end{abstract}

Keywords: Dispersion, PM10, Line source, Volume source, WRF. 